DOI https://doi.org/10.36059/978-966-397-174-2/84-102

\title{
EXTRACURRICULAR PEDAGOGY AS AN IMPORTANT COMPONENT OF PEDAGOGICAL STUDIES
}

\section{Sushchenko T. I.}

\section{INTRODUCTION}

The UNESCO report on Education for the 21st Century rightly states that lifelong learning should be based on four pillars: skills for cognition, competency, interaction and cooperation, and life skills on the whole. It means that childhood should be seen as training for life, and it should be organized to enable the formation of culture for vital self-determination in children and young people, their position in life, their worldview in relation to themselves and others. It should also develop the needs for self-cognition, self-understanding, self-realization in various kinds of creative activities; foster mutual understanding with other participants in the process of interaction, develop appropriate norms and rules for life, conscious attitude to basic vital needs. What is meant here is early, voluntary and deeply aware life creativity of children and young people, which is formed in extracurricular environment, at leisure - in the context of informal education, which, in connection with the worldwide popular concept "learning throughout life", is of utmost academic importance. Consistency of all means of pedagogical influence on the lives of children and young people in informal education is an essential prerequisite for logical and scientifically grounded, purposeful development of an individual, his / her spiritual, moral and intellectual activity in life.

Under certain social and pedagogical conditions, that are the subject of our study, extra-curricular education in the age of focus on a personality is the only way of spiritual, cultural enrichment of children and young people. We believe that extracurricular education techniques can create maximum favourable conditions for the fullest consideration and development of inborn qualities, form self-sufficient, creative personality at his/her own will and interests. This is the uniqueness and 
social significance of extracurricular pedagogical influence, its difference from all other educational processes.

Ukraine has always made a significant contribution to the development of academic framework for the development of extracurricular activities, represented by such well-known researchers as: P. Blonsky, N. Krupska, A. Makarenko; modern scientists L. Baliasna, O. Bykovska, V. Verbytsky, B. Kobzar, M. Koval, E. Kovbasenko, M. Koval, R. Naumenko, G. Pustovit, V. Redina, I. Rabchenko, O. Savchenko, M. Sidorenko, O. Sukhomlinska, O. Shapovalova, T. Tsvirova et al.

The purpose of the article is to show actual socio-pedagogical conditions and patterns of formation and development of extracurricular pedagogy as an important component of pedagogical studies.

The history of extracurricular institutes in Ukraine dates back almost a hundred years, but as a system it was formed in the late 60-70's, when the first educational complexes were created, research started, general methodological guidance was carried out by the Ministry of Education in Ukraine. In addition, a network of various extracurricular institutions of culture, sports, art, etc. has been growing.

Extracurricular education is a part of informal education for children and adults, it is any kind of extended educational activity throughout life that contributes to the activities of schools, colleges, universities, and other institutions that are part of the formal system.

\section{Extracurricular facilities are the most favourable informal environment for comprehensive development of children and youth in Ukraine}

For Europeans, informal education is a part of lifelong learning concept aimed at acquiring social roles, gaining experience in communication, leadership, language learning, teamwork and conflict resolution.

Ukrainian educational space has much to offer in terms of various forms of informal education, but the most common and the most widespread today is extracurricular education provided by out-of-school state, communal and private facilities for children and young people. 
Out-of-school educational establishments for children and youth belong to informal education of the European Association of Leisure Time Institutions. Since 2007 an Association of out-of-school educational institutions of Ukraine has been functioning. Its objectives are to create various amateur associations, folk groups, ethnographic expeditions, family workshops of applied arts, sports clubs etc.

Recently, such kinds of informal international and domestic forms of creative activity have intensified; they are as follows: international video conferencing, ecological creative associations, expeditions, exchange of cultural values, actions of charity, gatherings, associations of gifted children, marches of peace, studying history of the native land, "native roots", mother tongue, study of national progressive traditions. Much attention has been paid to the development of historical ties with other peoples of the world, peacekeeping activities.

Thus, out-of-school institutions have gained status of a full-fledged ring in the chain of continuous educational process, they provide children with broad and unconventional opportunities to improve their life, intensively shaping such important qualities as: children's positive attitude to their own lives and realization of themselves as individuals choosing favourite activities, which fit their inborn identity: ability for continuous spiritual and creative self-improvement; social responsibility, manifested in the care for family members, friends and other people; leisure culture.

Of particular importance today is the experience of extracurricular institutions in involving students in organizing exciting and large-scale events, such as: international teleconferences, environmental creative associations, expeditions, exchange of cultural values, charity events, gatherings, gifted children associations, marches of peace and others.

The results of our research show, that if children are engaged in practical creative activity that interests and excites them earlier and more frequently, they pick up natural desire for creative activity and knowledge sooner, and consequently, they deeper understand life, spiritual content of future work activity that leads to a more conscious manifestation of an active attitude towards improving the world around them. 
It is easy to see how life is different from ordinary life for those people who were lucky enough to learn the joy of solving the mysteries of the first interesting experiences in childhood, to feel success and their own abilities in exploring natural resources of their native land, or to create a revolutionary car model. And not so important is that car model itself, as the significance of child's spiritual energy spent, experienced, suffered, rejoiced in the process of expediently organized extracurricular creative activity.

The complexity of competitive market social relations has set forth conditions to learn and know much more information beyond school curricula. The world, which surrounds children and adults, is constantly changing, becoming more complicated and diversified. Therefore, one should not ignore the fact that schooling is not the only way to form a coherent personality. There are other important factors that play a significant role in enhancing creative potential of young people, in training them for practical social actions and global thinking, the formation of high cognitive culture, the development of inborn inclinations, mental and physical abilities, organization of meaningful leisure.

Out-of-school facilities are a rich and enabling environment for fullfledged development and recreation, interesting meetings, solution of vital problems where you can, for example, repair your bike or motorcycle, get advice on how to handle your computer, or a mobile phone, learn to use a sewing machine, learn culture of communication, get ability to earn money honestly, gain reading skills, or solve accessible and exciting research challenges, consolidate your skills in technology, sports, etc., i.e. all those things, which are interesting, important and necessary for life.

Therefore, the creation of an extensive system of social and pedagogical extracurricular activities in leisure time is of particular importance and urgency.

The leading place in solving these problems belongs to extracurricular institutions, which are intended to respond promptly to rapid changes in socio-economic society, to provide children with an opportunity to go beyond ordinary things in life, culture, nature, science, 
economy in order to maximize their opportunities to realize their creativity in an area that fits their inborn inclinations in the future.

To provide the abovementioned needs, more than two thousand extracurricular institutions operate in the education system of Ukraine, and the network of institutions of a new type is expanding, namely: extracurricular educational-research, creative-production centres, extracurricular centres of creativity for children and youth, tourism, local history, art schools, sports and technical schools, club facilities, etc. In many regions of Ukraine, new models of extracurricular institutions are being created to protect the rights of collaborating groups, including: children's and youth teams, theatre, social and pedagogical complexes, film centres, inter-school clubs, etc. These institutions are integrating with educational establishments of a new type: lyceums, gymnasiums, colleges, specialized schools, educational and industrial complexes, institutes and universities. Extra-curricular activities on the development of intellectual abilities of individuals, support of their creative talent are improved. Junior Academy of Sciences and scientific societies for students proved to be of high potential in Ukraine.

Deep qualitative changes have taken place in extracurricular activities in connection with the reformation processes of national school in Ukraine and raising children's awareness of their own involvement in the issues of their nation, ethnic group, people in general, folk wisdom and creativity. The networks of Junior Academy of Arts, Schools of Ethnic Studies, Folk Crafts, Kobza Schools are developing, and the number of children enrolled in various extracurricular institutions increases by fifty thousand annually.

Hundreds of thousands of children are involved in scientific-technical and industrial groups, scientific-technical societies, clubs for young technicians, designers, journalists. Many students attend science and technology camps during vacations, participate in competitions of the curious, designers and inventors. They have been involved in creatively tackling socially important environmental challenges, movement of rationalizers and innovators in businesses, improving learning environment, schools' and residential neighbourhood's life. Young chemists, hydrobiologists, zoologists, entomologists study river banks and sea shores from the perspective of modern achievements in biology, 
fauna and flora. Electronics engineers try their hand at developing microelectronics devices for agriculture and medicine, create optical indicators, storage devices, etc.

More than 2 million schoolchildren are regularly engaged in technical creativity, naturalist activities, sports, tourism in out-of-school establishments of Ukraine (there are more than 500). In addition, young inventors get assistance from young scientists, production rationalizers, pilots, sailors, aviators, astronauts, sponsors. Children's ensembles, theatrical, choral and other artistic groups are managed by professional artists, musicians, and directors.

Our long-term research has shown that people in their life play the roles that circumstances give them. A small role educates a small personality. A prominent, large-scale role develops a prominent, largescale personality, the formation of which is impossible without new social experiences and practices. With new social realities, children need a different life, other opportunities for creative expression, a more conscious responsibility for what will happen around tomorrow.

The leading place in solving these problems belongs to extracurricular institutions, which are intended to respond promptly to rapid changes in the socio-economic society, to provide children with the opportunity to go beyond ordinary things in life, culture, nature, science, economy in order to maximize their potential for creativity in an area that fit their inborn features in the future.

Recognizing the great social importance of extracurricular informal environment in youth education at this difficult time for Ukraine is a test of spiritual maturity of the government and society, a belief in productive and active search for the ways of solving the most important social problems.

The legislative framework (the Law of Ukraine "On Extra-curricular Education" and other legal acts) creates the basis and at the same time encourages extracurricular institutions to educate a humane, high-moral, responsible person. However, as stated in the Decree of the Ministry of Education and Science of Ukraine from December 10, 2008 № 1123 “On Amendments to the Regulations on the Organization of Individual and Group Work in Out-of-School Institutions" and the decision of the Ministry's Board of 27.11.2008, Minutes \# 14 / 3-3 “On the State and 
Prospects for the Development of Extracurricular Education", in conditions of acute lack of value orientations, there is an urgent need to improve extracurricular educational activity, while replacing standard educational measures for children and young people with purposeful enhanced moral education".

However, an analysis of existing extracurricular education practices shows that society and school have not yet been able to take advantage of the rich educational opportunities of modern extracurricular institutions; as a result, the number of failures has increased, and thousands of children's talents have not been realized.

We also have to observe such shameful phenomena, when wellfunded out-of-school facilities are spacious, beautifully decorated, but vacant. They employ people who are unable to make these extracurricular institutions joyful, attractive and necessary for the development of children. Therefore, absence of not only material conditions, but also lack of knowledge of extracurricular institutions staff, lack of skills in modern pedagogy of informal education, inability to find social programs for children give rise to formalism and helplessness of extra-curricular organizers.

Our special studies have identified such antipodes that can halt Ukraine's progressive development for decades. Thus, $61 \%$ of adolescents and high school students do not participate in social programs, while their life requires new social experiences and practices, meaningful extracurricular practices, opportunities for creative and meaningful expression, approaching something extremely useful, interesting and joyful. After all, extracurricular activity is in need, which requires responsibility for everything happening around, creating favourable psychological environment for the individual's harmonious development.

However, most children today face harsh realities of material and spiritual inequality. Many of them are left alone with their grief and poverty, without attention of adults or society. Only $41 \%$ of thousands of children polled today have access to true spiritual values. 6 out of 10 requests from young readers of the library are rejected. Most parents cannot buy a good book for their children. Students are not able to read 
books that their peers read. Language and literature teachers lack books of national and world importance.

On the whole, in our young state, unfortunately, such pedagogical mechanisms that would produce, support, consolidate, deepen, develop spiritual interests and needs, ideals, actions, communication at all sociohierarchical levels have not been established yet. On the contrary, the present environment often breaks, erodes, and replaces extracurricular sense of personal importance. Such unfavourable conditions slacken the process of displaying the most important and stable behavioural states of active self-expression, such as:

- positive attitude to the world in accordance with human principles and values, social and ethical norms;

- proper awareness of social role and place;

- stable healthy emotional feeling, experience of real relationships and interactions, human morality, analysis, evaluation, decision making, timely and responsible choices;

- integrity of consciousness, feelings, thinking and determination to fulfil beliefs, etc.

Lack of financing complicates the process reducing the material base. First of all, there are fewer premises, buildings for accommodation of these establishments. As a consequence, public out-of-school facilities stop functioning because of insufficient funding (or, more precisely, the absence of such) for the creation of material and methodological, technological base, latest information and computer facilities of educational activity; frequent change of subordination of some extracurricular institutions (for example, children's and youth clubs at the place of residence) to different management structures reduces management potential, cooperation, control and, ultimately, the quality of educational activity.

Humanization of educational environment of out-of-school educational establishments is only at its primary stage of implementation, so methods of coercion in administration have not yet been eliminated in pedagogical practice.

In order to identify the conditions for the effective development of children and young people in out-of-school educational establishments, we interviewed 416 educators, heads of groups working in children's and 
youth clubs of the Centres for Children and Youth Creativity. 22\% of the respondents said that in such difficult political and socio-economic situation in the country, increasing immorality, crime, devaluation of human values, life, education, teacher's authority comedown, increasing aggressiveness and nihilism of young people, it is very difficult to form positive qualities in youth.

Among the most important reasons for the decline the following were mentioned: the need to introduce different types of stimulation for teachers, who increase their theoretical and methodological level and improve pedagogical skills (50\% of respondents); coordination of actions and educational influence of all social institutions that carry out extracurricular work (58.3\%); development and implementation of new methodological advances and technologies adapted to modern social processes $(66.7 \%)$, etc.

The survey showed that only $41 \%$ of extracurricular educators put into practice methods of discussions and mini-discussions, $50.4 \%$ modelling of pedagogical situations, $25 \%$ - problem-finding methods, $16.7 \%$ - workshops. Most commonly used traditional information methods of schooling (narration, explanations, conversations), complex mass events, which quite often suppress active mental and emotional activity of students, reduce the impact on the development of children's creative abilities; $22 \%$ of respondents noted that complex political and socio-economic factors of today, devaluation of human life, ideals, education, teacher's authority comedown, the growth of asocial and aggressive manifestations in our society significantly reduce the results of educational activities in extracurricular environment. Instead of such modern-day methods as aformation (relying on strong personal-willed qualities in the development of children's creativity) or extrapolation (transfer to the future), out-of-school facilities and schools still use outdated technologies. Hence, it is clear why we get such logic of feelings, actions and content of life of children, even in leisure, extracurricular environment.

In our opinion, the greatest danger of modern society is the use of culture for the purpose of enrichment. Spiritual culture becomes a commodity. Mass bourgeois culture became widespread. There is a danger of losing the most essential and necessary: genuine interest in 
antiquity, folk traditions, decent relationships, and ultimately, in the highest value - people.

It is quite natural that dangerous socio-pedagogical consequences are also found in the system of school education, in particular, such as formalism of education, authoritarian style, separation of education and upbringing from the world and national culture, violation of hereditary principles in family upbringing, children preschools, primary and secondary schools, vocational colleges, universities, poor coordination of school and extra-curricular activities, mass media, poor quality of methodological and methodical materials, manuals on educational problems.

Rescuing children from moral and spiritual degradation requires a transition to a truly humane extracurricular education system, transforming out-of-school facilities into cultural and spiritual centres capable of enhancing the lives of children and young people in microsociety by educating social environment as a whole. This is the main condition for transforming our entire society into a caregiver.

The influence of modern media on the upbringing of the younger generation cannot be overestimated. Some representatives of the new sociological theory of the "information society" give these media a priority in the system of social relations, because they have become an indispensable element of everyday life, have become an organic part of the living environment.

Media not only cover all the aspects of children's life: their everyday life, way of life; they began to change their moral face. There is great potential for this in television, by means of which "live viewing" of objects that are not normally observable is carried out, but also of human relationships. However, contemplation alone is not enough for children to have a correct understanding of the most significant sides of objects, to form some positive generalizations. It requires focused pedagogical attention, which would be based on data from medicine, psychology and medialiteracy (awareness of the specifics of television, psychological and pedagogical features of the perception of video information by students). 


\section{Theoretical substantiation of the essence of a new branch of studies - extracurricular pedagogy in modern society}

Our long-term research demonstrated that most of the pressing issues of spiritual enrichment of extracurricular informal environment are related to the acceleration of the official recognition of the socially important role of extracurricular pedagogy at the official level, which will help to accelerate the process of turning extracurricular education in Ukraine into a temple of children's dreams and happy creative selfaffirmation.

A new provision on extra-curricular educational institution of Ukraine, as an institution designed to give children and adolescents additional education, to provide the needs for creative self-realization and organization of meaningful leisure, suggests different levels of formation of creative personality. It should stimulate harmonious development of children taking into account social and pedagogical situation, focus on individual development, interests of children and their parents, which requires a truly humane attitude to a child's personality, construction of extracurricular pedagogical process for recognition child's identity and self-value in compliance with special laws of extracurricular pedagogy.

An attempt has been made to resolve these issues on the basis of experimental conceptual position, which is as follows: optimality of pedagogical influence of extracurricular institutions of any profile on the comprehensive development of children is ensured by mutual spiritual enrichment of teachers and children, creation of a psychologically favourable environment of educational attitudes, high level of educational relationships culture and intellectual co-creation.

The out-of-school pedagogical process highlights the following important aspects of child's nature as a priority:

* uniqueness and inimitability (realization of the child's right not to be like everyone, to cognize oneself and be interested in oneself and other people, to realize oneself by a special program and individual trajectory of personal development and self-development);

* creativity (realization of the right to creative initiative, personal autonomy and responsibility, the right to compare oneself with yesterday's and future's self, with other peers and adults, to compare 
their lifestyle with the lives of those who consider it a standard in the process of exciting creative activity);

* inner freedom (realization of the right to choose, which envisages expansion of the branched sphere of creative self-expression of a child after classes, to understand what he or she is capable of due to free choice of the standard of morality and excellence);

* spirituality (realization of the right to respect, precious attitude, love and creativity, assistance to other people in their self-improvement; variable models of children's creativity and set of social roles).

Thus, on the basis of theoretical analysis of scientific and literary sources and long-term experimental research we have proved a legitimate need to set up extracurricular pedagogy as a separate independent field of pedagogical studies. We have described the subject of extracurricular pedagogy, its basic theoretical provisions with reference to the nature of extracurricular pedagogical process, substantiated its basic concepts, principles and regularities of extracurricular pedagogical process, characterized pedagogical conditions of effectiveness of mass work with children in extracurricular environment, new functions of extracurricular teacher and head of extracurricular institution, regularities of extended education and development of children in leisure environment, covered the issues of management in modern extracurricular pedagogical process.

Significantly, more and more theoretical sources are confirming this. V. Vernadsky proved that spiritual manifestations of a person are of great importance, they are of utmost priority, corresponding to the properties of higher forms of human life. Therefore, the reference to the category "extracurricular pedagogy" is a natural consequence of the fruitful development of general pedagogical theory and a more thorough study of extracurricular environment, as a phenomenon of spiritual renovation of the whole society.

Such an approach to the strategy of constructing extracurricular pedagogy is inherent in its nature: prompt response to the realities of life without orders from above, to the newly emerged interests of children, their needs and intentions. And if we delay the recognition of the need for such socially meaningful pedagogy at the official level, extracurricular institutions will remain vacant and spiritual life of 
children impoverished. Therefore, it is time to fill in the gaps in education with extracurricular pedagogy in Ukraine.

Let's consider its difference from school pedagogy.

Extracurricular pedagogy is a branch of pedagogical science that studies the patterns of comprehensive development and creative selfrealization of individuals in terms of their free time and leisure.

The term "extracurricular pedagogy" is a neologism that has recently become widespread. It is often used by philosophers, educators, social psychologists, culturologists, journalists and many other professionals who are somehow involved in the procedure of raising children and young people in extracurricular environment in leisure process.

Its humanistic nature indicates precious attitude towards children, understanding this concept as a sensitive attitude of adults to children's interests and experiences, the desire for agreement and rapprochement with the child, ability of extracurricular teachers to offer children such a form of extracurricular vital activity. It is this attitude towards the child that stimulates the disclosure of his or her identity in the best forms of creative expression; it is a way out of the space of compulsory educational communication and gradual development of the spiritual potential of the individual.

This is, after all, so called $e x$ a $l$ t a $t i$ o $n$ of an individual, enhancement of his or her personal status in the eyes of family members, friends and other people, himself/herself due to creative self-realization.

Organization of extracurricular pedagogical process means:

1. An extensive system of creative expression for children, maximum conditions for purposeful development of their creative opportunities, which involves, first of all, removal of all kinds of restrictions, barriers that impede intellectual initiative of children, their creative expression. Unnatural wretchedness of ideological, emotional life is not the case for such a pedagogical process. On the contrary, its peculiarities are as follows: richness of impressions, children's imagination, such questions, which children themselves are eager to answers and tirelessly under the guidance of extracurricular teachers, seek for the answers and find them. In such pedagogical process, reproductive activity of children necessarily includes elements of creativity. 
2. Teacher in extracurricular pedagogical process are not programoriented, they are child-oriented, i.e. they take into account children's mood, inner state, creating conditions for their full disclosure and selfdevelopment of the inner forces and abilities of children through liberation of their thoughts.

3. It is a process in which the activity of the teacher is organically combined with the activity of children in a single active cognitive process in the conditions of cooperation and spiritual interaction.

4. According to Sh. Amonashvili, the basis of the integrity of pedagogical process is children's development in various forms and in full conformity with the formation of their vital forces. To carry out such a process means "to involve the inborn children's inclinations to an enhanced and a bit pre-term activity, to involve delicately, satisfying the needs for the child's desire for development, will, and adulthood. This is an individualized and humane approach to a child in pedagogical process, and it gives birth to collaboration of the teacher with the students (3, p. 201).

5. In this regard, a model characteristic of extracurricular pedagogical process is child's free choice, flexibility and accessibility, which allows changes in the parameters of pace, volume and subject content of the curricula, free choice of the learning pace, in order to enable children to manage their time reasonably, perform certain types of work faster, etc.

6. The ideal extracurricular pedagogical process is almost imperceptible to the child.

Considering the general logic of conceptual approach to the organization of the inspirational extracurricular pedagogical process, it is necessary to update and reform the system of state control, criteria for evaluating the performance of extracurricular institutions, current Regulations for extracurricular institutions and the contest "Extracurricular Teacher of the Year" and other documents.

In other words, a new paradigm of accounting for the results of work of teachers of out-of-school institutions does not reject the previous one, on the contrary, it absorbs the former, paying special attention to such important indicators as:

- whether extracurricular pedagogical process involves children, all aspects of their life and to what extent, how much this process becomes a 
sense of their life; what kind of human culture, to what extent, with what depth and with what passion children acquire; what attitudes children create; to what extent pedagogical process contributes to the development of children's inborn features (Amonashvili, Sh. A. Reflection on Humane Pedagogy. - M.: Shalva Amonashvili Publishing House. - 1995).

Thus, taking into account modern theoretical and methodological approaches, the main tasks of teachers in out-of-school institutions should be:

- to think professionally in the categories forward-looking policy, getting consistent progression and promotion in professional excellence;

- to train their pupils to be successful in the twentieth century, giving them all possible assistance;

- to encourage, inspire, enthral children with creative activity and cooperate with them on the principle of: less reprimands, more encouragement;

- to make recommendations to children clearly and easily accessible so that they are comprehensible for everyone;

- to form creative children's associations and communities in extracurricular institutions, using the principle of "wise authority of the team", suggested by V. Sukhomlynsky;

- to encourage children to believe in their own strengths and abilities, to develop their creative personality and their personal status comprehensively.

So, out-of-school pedagogy is a kind of reference for professional introspection and formation of creative approach to systematic, theoretical and methodical support of extracurricular pedagogical process taking into account methodological practices of modern extracurricular pedagogy.

In the conditions of a legal democratic state, purposeful education of large-scale, creative and comprehensively developed personalities, training of life leaders, not wordless performers, upbringing of true intellectuals is the prerequisite for the productive life. This approach to implementation is not temporary. It is the ideal of a progressing life. 
None of current structures of the education system in its old, immutable form can solve these problems because of the functional approach to the individual.

Therefore, our reference to the category "extracurricular pedagogy" is a natural consequence not only of the fruitful development of the general pedagogical theory, but also of a more thorough study of the features of modern extracurricular environment, which with the help of extracurricular pedagogy can become a phenomenon of spiritual renovation of the whole society.

It is logical that the collocation "extracurricular pedagogy" is associated with joyful communication, spiritual and psychological comfort and something that attracts and enthrals high human tasks and perspectives, its humane character, which forms its value and priority among the factors of "human expression" (V. I. Vernadsky). That is why extracurricular pedagogy gives preference to subject-subject relationships between educators and children, their collaboration and cocreation, shared choice of learning goals, interpersonal contacts and empathy. It is based on deep knowledge of children's interests and needs, which suggests: involving children in real co-creation, intellectual dialogue; harmonization of communication, success, ability to feel free in case of failure, even to have the right to failure.

Extracurricular pedagogy does not imply any compulsion or fear. On the contrary, it supports the development of independent thought, the development of a system of dialogical methods of co-creation and intellectual tension, provides imaginary experiments for younger school children, intellectual games, reception "if", flexible and harmonious combination of individual, group, team, self-activity, where children are engaged in love and are able to rise in their own eyes as a creative personality.

That is why extracurricular pedagogy plays a leading role in general pedagogy. Its purpose is not only to provide knowledge but also to enrich personal life competences, it objectively influences successful life-giving and vital activity of children in the future.

The peculiarity of leisure influence on the development of personality is that children do not reproduce what they are learning, they do not work for evaluation. Due to its unique character extracurricular activities 
held by teachers develop the acquired knowledge and social experience, complements and improves it. This is the law of creative behaviour that is against functional approach to the child, one-sidedness, fragmentation, intellectual overload and coercion.

Co-creation is built in extracurricular environment on the basis of spiritual unity of the personality of a sociable community, attraction of children to creation, immersion in the subtlety of theory and practice, love of the subject, compulsory right to feel free in the independence of thought, approval and implementation of ideas coming from each child's activity (child development, inventions are an important element of extracurricular learning).

Therefore, out-of-school pedagogy is of personal character, it considers education and upbringing of a child in extra-curricular institutions not only as a task of great didactic value, but also as an appeal to each individual in order to establish co-operation. A standard activity-filled class that has no elements of surprise or novelty is doomed to failure in an extracurricular environment.

Therefore, teaching didactics of pedagogical process in extracurricular institution is oriented on spiritual enrichment and creation of such an educational environment, which can provide a high level of creative independence for children. It becomes so "mature" in such a process that it has the power and ability to shape and nurture itself throughout life.

It is quite natural: extracurricular pedagogy has absorbed much of what is gained in general pedagogy, in particular, school pedagogy. However, it is not a mere copy of the principles, forms and methods of schooling, but has its own specificity and fundamentally other laws that distinguish this type of pedagogical activity (not mere actions or operations, but activities) from another.

There are other reasons to consider extracurricular pedagogy as an independent branch of pedagogical science and practice due to the specifics of its purpose, object, subject, principles, tasks and conditions for the child's development, education and upbringing. The right to its existence is proved by life itself. Extracurricular pedagogy elucidates and studies the patterns of effective self-realization of the creative personality in the sphere of leisure. 
Like all other fields of study, it has its own specific categories, general concepts that reflect its universal properties and attitudes of objective extracurricular reality, general patterns of development of creative personality.

Such categories are as follows: extracurricular pedagogical process, leisure environment, free choice, sanogenic (improving) individual approach to child's development, admiration, co-creation, comprehensive development, psychological comfort of communication, etc.

Thus, it is quite logical, along with pedagogy of pre-school education, vocational education and higher education pedagogy, which traditionally retain the right to exist as independent branches of pedagogy, to legalize the right for existence of extracurricular pedagogy in order to ensure the most important principle of continuity, its integrity, taking for granted that legging behind of any branch of pedagogy impoverishes and delays the development of all others.

There is every reason for this, including theoretical ones. In the last decade more than ten doctoral and hundreds of $\mathrm{PhD}$ dissertations on the most important problems of extracurricular pedagogy have been submitted in Ukraine. The most famous in Ukraine and beyond are the doctoral research, conducted by O. Bykovska, V. Verbitsky, R. Naumenko, H. Pustovit and et al., aimed at creating a better quality of life for children in Ukraine on the basis of creative initiatives of pupils and educators, good will of everyone on the principle of selforganization and the widest possible expansion of social experience, spiritual unity in joint exciting creative activity and recreation.

At one of the most powerful pedagogical universities of Ukraine M. P. Drahomanov University, the world's first Extracurricular Education Department headed by Doctor of Pedagogical Sciences, Professor Bykovskaia O. V., is already functioning. She devoted her activity to this issue. Similar departments are opened in other institutions of higher education.

\section{CONCLUSIONS}

1. More and more sources are opening up that prove the great importance of extracurricular pedagogy in the successful solving of 
current problems of pedagogy of continuous informal education in Ukraine as a whole.

2. Focus on the category "Extracurricular Pedagogy" is natural not only due to the fruitful development of the general pedagogical theory, but also due to a more thorough study of modern features of extracurricular environment, which with the help of extracurricular pedagogy can become a phenomenon of spiritual recovery of our society.

3. Legalization and recognition of general and specific pedagogization in extracurricular informal environment is of great social importance for the development of children and young people in this difficult time for Ukraine and can be considered a test for spiritual maturity of Ukrainian society.

\section{SUMMARY}

The article substantiates regularity of existence and development of a new field of studies - extracurricular pedagogy. An updated conceptual system of its basic notions with their definitions is suggested. The article is based on the results of long-term research of leisure sphere and extracurricular pedagogical process.

\section{Information about the author: Sushchenko T. I.,}

Doctor of Science in Professional Education, Professor, Professor of Education and Management of Educational Institution,

Classical Private University 70b, Zhukovskoho str., Zaporizhia, 69002, Ukraine 